Artigo

\title{
Rachar as palavras em aulas de matemática: (com)posições de sentidos
}

\author{
Crack the words in math classes: (with)positions of meanings
}

Romper palavras em clases de matemáticas: (com)posición de significados

\author{
Virgínia Crivellaro Sanchotene ${ }^{1}$ \\ [0000-0001-7083-0622] \\ Gilberto Silva dos Santos ${ }^{2}$ \\ [0000-0003-4616-9891]
}

\section{Resumo:}

Este texto tem como objetivo tensionar o uso das palavras em aulas de matemática. Discute-se a potência de rachar as palavras, discuti-las em âmbito etimológico, léxico-semântico, histórico. Para isso, trabalha-se com o procedimento genealógico no exercício de debruçar-se sobre as palavras e seus significados. Dos lugares provisórios de estar docente, docenciar-se, questiona-se quais os efeitos produzidos pelo deslocamento de uma posição estruturalista para um âmbito pós-estruturalista, especialmente com autores das filosofias da diferença, para pensar o atravessamento da linguagem e atravessar a linguagem, em imanência - em aulas de matemática. Sob angulações do filósofo Friedrich Nietzsche, distanciamo-nos da concepção neutra e transparente da linguagem a fim de estabelecer relações menos estreitas e criar condições outras de pensamento com aulas de matemática. A ampliação de vocabulário, a formação de palavras por meio de um radical comum ou por prefixação/sufixação e a polissemia se apresentam como ferramentas para pensar um uso menos automático e mais compositivo das palavras, tomado aqui como uma atitude ética de inserção da docência em solo movente, no dinamismo que lhe é próprio.

Palavras-chaves: Linguagem. Ensino de matemática. Significação. Nietzsche. Deleuze.

\begin{abstract}
:
This text aims to tension the use of words in math classes It discusses the power of crack the words, discussing them in an etymological, lexical-semantic, historical context. For this, the genealogical procedure is developed in the exercise of observing the words and their meanings. From the provisional places of being a teacher, becoming a teacher, one wonders what are the effects produced by the change from a structuralist position to a post-structuralist scope, especially with authors of the philosophies of difference, to think about the passage of language - and cross language, in immanence - in math classes. Under the views of the philosopher Friedrich Nietzsche, we moved away from the neutral and transparent conception of language in order to establish less close relations and create other conditions of thought with mathematics classes. The expansion of vocabulary, the formation of words by means of a common radical or by prefix/suffix and polysemy are presented as tools to think about a less automatic and more compositive use of words, taken here as an ethical attitude of insertion of becoming become a teacher on mobile soil, in his own dynamism.
\end{abstract}

Keywords: Language. Mathematics teaching. Significance. Nietzsche. Deleuze.

\footnotetext{
${ }^{1}$ vicrivellaro@hotmail.com, Mestre em Educação, Professora e doutoranda em Educação, Prefeitura Municipal de Porto Alegre e Universidade Federal do Rio Grande do Sul, Porto Alegre/RS/Brasil.

2 prof.giba.mat@gmail.com, Mestre em Educação em Ciências, Professor e doutorando em Educação em Ciências, Prefeitura Municipal de Porto Alegre e Universidade Federal do Rio Grande do Sul, Porto Alegre/RS/Brasil.
} 


\title{
Resumen:
}

Este texto tiene como objetivo enfatizar el uso de palabras en las clases de matemáticas. Discute la potencia de romper palabras, discutiéndolas en un contexto etimológico, léxico-semántico e histórico. Para esto, el procedimiento genealógico se trabaja en el ejercicio de inclinarse las palabras y sus significados. Desde los lugares provisionales de ser maestro, vuelvete un maestro, uno se pregunta cuáles son los efectos producidos por el cambio de una posición estructuralista a un ámbito postestructuralista, especialmente con los autores de las filosofías de la diferencia, para pensar sobre ser atravesado por el lenguaje - y atravesar el lenguaje, inmanente - en clases de matemáticas. Bajo los puntos de vista del filósofo Friedrich Nietzsche, nos alejamos de la concepción neutral y transparente del lenguaje para establecer relaciones menos estrechas y crear otras condiciones de pensamiento con las clases de matemáticas. La expansión del vocabulario, la formación de palabras a través de un radical común o mediante el prefijo / sufijo y la polisemia se presentan como herramientas para pensar en un uso menos automático y más compositivo de las palabras, tomado aquí como una actitud ética de inserción de la enseñanza en suelo en movimiento, en su propio dinamismo.

Palabras clave: Lenguaje. Enseñanza de las matemáticas. Sentido. Nietzsche. Deleuze.

Mover-se é viver, dizer-se é sobreviver. Não há nada de real na vida que o não seja porque se descreveu bem (PESSOA, 2019, p. 34)

\section{Primeiras palavras: para um meio de conversa}

\author{
pa.la·vra ${ }^{3}$ \\ (latim parabola, -ae) \\ substantivo feminino \\ 1. [Linguística] Unidade linguística com um significado, que pertence a uma classe \\ gramatical, e corresponde na fala a um som ou conjunto de sons e na escrita a um \\ sinal ou conjunto de sinais gráficos. = TERMO, VOCABULÁRIO. \\ 2. Mensagem oral ou escrita (ex.: tenho que Ihe dar uma palavra). \\ 3. Afirmação ou manifestação verbal. \\ 4. Permissão de falar (ex.: não me deram a palavra). \\ 5. Manifestação verbal de promessa ou compromisso (ex. confiamos na sua palavra). \\ 6. Doutrina, ensinamento. \\ 7. Capacidade para falar ou discursar. \\ interjeição \\ 8. Exclamação usada para exprimir convicção ou compromisso.
}

O objetivo deste artigo é discutir possibilidades de estudos morfológicos, etimológicos e léxico-semânticos das palavras em aulas de matemática, como maneira de incidir na tendência monossemântica que comumente trabalhamos, devido a uma herança vinculada ao pensamento referencial da linguagem. Consideramos que uma apropriação dessas ferramentas de estudos da linguagem se faz potente na medida em que apresenta aos alunos que as palavras são construções humanas, datadas, e que não se esgotam nas possibilidades de sentido historicamente consagradas, abrindo-as a relações menos estreitas e operando, assim, possibilidades outras de pensamento considerando que "tudo veio a ser; não existem fatos eternos: assim como não existem verdades absolutas" (NIETZSCHE, 2005, p. 16). O

\footnotetext{
${ }^{3}$ As definições que conversam com o texto em todas as seções foram retiradas do site dicionário.priberam.org (Dicionário Priberam da Língua Portuguesa).
} 
pensamento, aqui, é tomado como criação, pois "um criador é alguém que cria suas próprias impossibilidades, e ao mesmo tempo cria um possível" (DELEUZE, 2007, p. 167). Desejamos a criação de novos possíveis.

Mas por que discutir a monossemia em matemática? Por que rachar as palavras, para usarmos o termo cunhado por Deleuze no livro Conversações (2007, p. 105), em aulas de matemática? Machado aponta que o ensino, muitas vezes, aborda a matemática "como uma linguagem em que a hipertrofia da dimensão sintática obscurece indevidamente o papel da semântica, que é deixada em segundo plano" (MACHADO, 2011, p. 22). Segundo o autor, a monossemia e a linguagem asséptica da matemática são garantidas pela exclusão de sentenças que não possam ser classificadas como verdadeiras ou falsas, tratando apenas de ideias claras e distintas, na esteira do pensamento cartesiano (MACHADO, 2011). Como e por que operar essa uma inflexão nessa relação sintático-semântica? Uma inflexão "é uma inversão na relação de forças em si mesma. É o que ocorre na suspensão da valoração positivo/negativo, porque neste ponto a posição não pode ser julgada por tais parâmetros, ao transvalorar-se" (SANCHOTENE, 2017, p. 77).

A discussão que propomos trata da inserção dos estudos contemporâneos da linguagem, do discurso e dos sentidos no campo da Educação Matemática, por motivos diversos. Consideramos estudos contemporâneos sob dois aspectos: Primeiro, em relação a Friedrich Nietzsche (1844-1900, séc. XIX) e sua crítica ao pensamento Moderno. Segundo, emerge da multiplicidade de autores dos séc. XX e XXI, tais como Michel Foucault e Gilles Deleuze, que, com Nietzsche, propõem rupturas com a linearidade entre identidade e diferença; com a representação.

Elucidamos dois dos aspectos que nos orientam a inscrever nossa docência em solo compositivo com a linguagem: Em primeiro lugar, porque usar as palavras em aulas de matemática é inevitável. Não há aula que se produza sem a interpelação da linguagem. Ainda que essa aula possa envolver outras linguagens - dança, teatro, música, álgebra - não se pode pensar um ensino básico de matemática que se prive do uso das linguagens oral e escrita. Não escapamos da linguagem. Isto posto, propomo-nos discuti-la; colocá-la em evidência, sem restringi-la à sua forma descritiva - como fazem as filosofias da representação.

Em segundo lugar, trata-se de um posicionamento ético da docência em matemática. Aqui, ética assume o caráter apresentado nos estudos foucaultianos, como maneira de problematizar a si mesma e considerar-se imersa no dinamismo que se faz aula e fabula saberes. A ética nos implica com nossa maneira de agir, de docenciar (AURICH, 2017; SANTOS, 2020), para além das prescrições morais, indo "[...] tão longe, que nos permitiríamos conceber a própria origem da linguagem como expressão de poder [...]" (NIETZSCHE, 2009, p. 17).

Mas não é isso que diversos documentos oficiais rogam e que tendências estruturalistas norteiam: a importância de compreender o significado das palavras para melhor compreensão de enunciados e do uso da História da Matemática como maneira de contextualizar conteúdos específicos ou mesmo justificá-los? Não é disso que se trata o estudo da linguagem nas vertentes pós-estruturalistas, conforme veremos na sequência, assim como não é este o sentido de significado que assumimos.

O significado é tomado, aqui, como um, e apenas um, modo de compreender uma palavra. Um sentido, aliás, bastante restrito. $O$ estudo das palavras em aulas de matemática proposto não deve ser tomado como modo de introduzir um conteúdo ou a nível de curiosidade, mas como constitutivo de uma maneira de ensinar matemática calcado nas tendências pós-estruturalistas, alicerçados especialmente em autores das filosofias da 
diferença - aqueles que tomam a diferença como "multiplicidade heterogênea, potência de invenção do imprevisível e força de produção da novidade" (CORAZZA, 2015, p. 107), ao problematizar sentidos últimos e invariantes. Enquanto através da dialética podemos circunscrever "o campo da vida e do pensamento a um 'isto e não isto', temos a diferença propondo "isto e aquilo e mais aquilo..."” (CORAZZA, TADEU, 2003, p. 11).

Heuser explica que as filosofias da diferença não buscam superar ou ultrapassar a tradição metafísica, mas "de interrogá-la; de pôr em questão os seus sentidos e sem sentidos, seus paradoxos intrínsecos, as suas opressões; de compreender a metafísica como um grande texto que está em aberto a novas interpretações" de modo a "estarmos atentos à etimologia e aos múltiplos sentidos das palavras mas também aos efeitos que escapam das intenções do autor-sujeito, aos sintomas e às contradições (HEUSER, 2008, p. 62).

Interessa-nos a linguagem não somente para que um aluno decifre códigos e resolva problemas, como amplamente se discute na Educação Matemática, mas que ele a compreenda como produtora de sentidos; constituidora da realidade (RÉGNIER; BELLO; KUZNETSOVA, 2018). Trata-se de uma inscrição de nosso docenciar no território da diferença (pura).

\section{0 problema da linguagem}

"Movida pela crença de que a forma fundamental do pensamento é a mesma de suas manifestações por palavras, desde cedo, a filosofia não hesitou em identificar discurso e realidade", ao produzir conhecimento a partir da "dimensão apofântica da linguagem, tomando enunciados verbais por verdadeiros ou falsos, em função de descreverem corretamente ou não o mundo" (BARROS, 2008, p. 10). Filosofias representacionistas buscam identificação entre o dizer e o real produzindo o conhecimento a partir do reconhecimento, de um espelhamento do mundo através da razão, expressa pela linguagem.

Filósofos como Schopenhauer, Nietzsche e Kiekegaard, no final do século XIX, problematizam os paradigmas modernos da racionalidade e dos fundamentos últimos da verdade. Esses pensadores influenciam Lyotard, Foucault, Deleuze e Derrida, entre outros, que criticam o caráter hegemônico da razão, os grandes sistemas discursivos, os significados transcendentais, a ilusão metafísica da universalidade, a concepção essencialista da linguagem. Marcondes sugere que "somente quando se problematiza a noção de representação, ao final do período moderno, que se abre caminho para a valorização da linguagem" (MARCONDES, 2017, p. 39).

O cunho pós-estrutural rompe com a transparência entre palavra e realidade. Ao invés de dizer aquilo que o objeto é, atravessamos fronteiras no âmbito de produzir o que chamamos de realidade à medida que a interpelamos pela linguagem. Inserir a docência em matemática neste viés passa pela crítica aos significados estanques e disciplinares que as palavras assumem em aulas. Desejamos forjar movimentos para que novos possíveis no campo léxico-semântico possam ser produzidos com o que se faz aula, por transbordamentos.

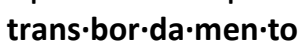

(transbordar + -mento)

Substantivo masculino.

Ato ou efeito de transbordar. = TRASBORDAMENTO.

trans·bor-dar

(trans- + borda + -ar)

verbo transitivo

1. Sair para fora de (ex.: o rio trasbordou as ribas). 


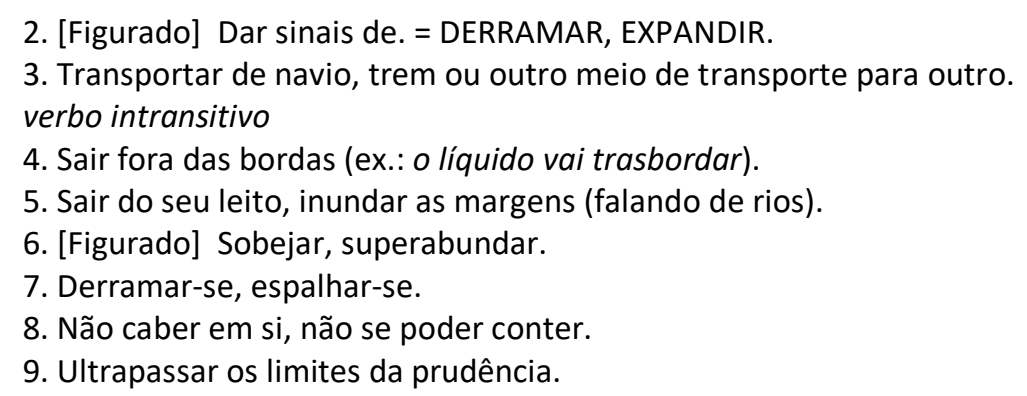

A visão de currículo que abraçamos, nomeada pós-estruturalista, "com seu pressuposto de primazia do discurso e das práticas linguísticas", discute a avaliação epistemológica baseada na dualidade verdadeiro-falso, considerando a "criação simbólica" como um "processo aberto e vulnerável" (SILVA, 1999, p. 14-15). Nesse sentido, consideramos que as concepções que tomam a diferença como essencialista fixam, imobilizam, paralisam "o trabalho incerto e indeterminado da linguagem", e desse modo reduzem a prática humana de significação "ao registro e à transmissão de significados fixos, imóveis, transcendentais" (SILVA, 1999, p. 15).

Sugere-se promover uma atenção às palavras em aulas de matemática, apoiados na ideia de que, ao compreender que elas carregam histórias e não possuem significado estanque, o aluno amplia as possibilidades de (des)construção de sentidos, de formulação de novos sentidos, num âmbito relacional e diferencial da linguagem. $O$ estudo das palavras - e aqui incluímos ler, escrever, discutir - é tomado como ferramenta para criação de vinculações menos estreitas com a linguagem, o que passa necessariamente pela criação de um inventário de signos, significados dados e etimologias, para que se possa trabalhar sobre e estabelecer possibilidades outras.

Deslocamo-nos de uma posição estruturalista que compreende a linguagem como representação de uma realidade dada, em que as palavras carregam significados como propriedades; para uma posição pós-estruturalista, ao "teorizar sobre a linguagem e o processo de significação" (SILVA, 2005, p. 117), compreendendo que discussões neste âmbito implicam diretamente interpretações. A partir de uma pragmática da linguagem, acrescentase "à consideração do contexto a ideia de que a linguagem é uma forma de ação, e não de descrição do real" (MARCONDES, 2017, p. 53).

No pós-estruturalismo, "o processo de significação continua central [como no estruturalismo], mas a fixidez do significado que é, de certa forma, suposta no estruturalismo, se transforma, no pós-estruturalismo, em fluidez, indeterminação e incerteza" (SILVA, 2005, p. 119). Essa fluidez possibilita que a representação seja tensionada, viabilizando modos de pensá-la para além do dualismo identidade e diferença (o eu e o não eu, por exemplo), rompendo com as generalizações oriundas de um representar verdadeiro para potencializar as verdades provisórias (NIETZSCHE, 2008, 2017). Tomaz Tadeu nos apresenta que a concepção pós-estruturalista vê o processo de significação como indeterminado e instável, e que essa atitude "enfatiza a indeterminação e a incerteza também em questões de conhecimento", sendo o significado, nesta perspectiva, "cultural e socialmente produzido" (SILVA, 2005, p. 123).

Discutir as palavras do campo léxico-semântico da matemática propicia condições de potencializar a matemática tanto dentro de sua disciplina, como fora dela - não é por acaso que Deleuze, por exemplo, extraia da matemática conhecimentos para construir seus conceitos filosóficos. Rachar as palavras, operar desconstruções - e reconstruções - de seus 
sentidos nos possibilita redimensionar o que pensamos e o modo como operamos nosso pensamento - e propomos que esta maneira de trabalhar com a linguagem se estenda às nossas aulas de matemática.

Corroboramos com Tomaz Tadeu da Silva, que nos apresenta que o educador crítico da diferença - tomada aqui como diferença pura, imanente, sem mediação - abre "o campo do social e do político para a produtividade e a polissemia, para a ambiguidade e a indeterminação, para a multiplicidade e a disseminação do processo de significação e de produção de sentido" (SILVA, 1999, p. 10). Estabelecer a linguagem como foco de atenção e estudo produz efeitos de formação de saberes, de conhecimentos, de incidência em poderes, de produção de subjetividades. (CORAZZA; TADEU, 2003)

O texto-currículo precisa ser tensionado, ao lado de outros tantos textos que o constituem, como normativas, orientações e parâmetros curriculares, livros didáticos, para que sejam possíveis outras interpretações para palavras como aula, docência, ensino, educação...

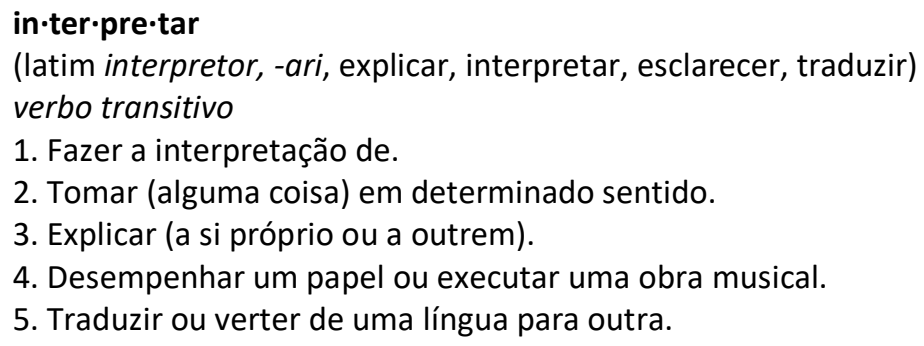

Mas o que seria a filosofia da diferença? Em um primeiro momento, o artigo definido $a$ deveria ser trocado por uma, considerando a pluralidade das filosofias da diferença. A seguir, reformulamos a pergunta sem o verbo essencialista "ser", e, assim, sem perguntar o que é, mas como funcionam ou o que podem as filosofias da diferença. Quais efeitos produzem? Quais possibilidades nos abrem? De que maneira nos implicam? É como se o solo fossem as filosofias pós-estruturalistas, mas diferente de outras filosofias contemporâneas, não estabelecemos residência, mas tornamo-nos nômades.

Uma didática inserida nas filosofias da diferença, como "multiplicidade heterogênea, potência de invenção do imprevisível e força de produção da novidade", em uma "direção tradutória dos atos curriculares" (CORAZZA, 2015, p. 107-108) só se faz fazendo. Ou seja, não é possível tomar a incerteza, a invenção, a diferença em aulas de antemão, trata-se de docenciar no cotidiano e indiferençar ${ }^{4}$ aula e vida. "Diferença na escola é tratada desde os processos de criação tradutória dos elementos de partida, produzidos por ciências, filosofias e artes" (SPERB; CORAZZA; DINARTE, 2017, p. 338). Traduzir, aqui, assume caráter interpretativo, de produção de sentidos.

Como nos diz Heuser, a convergência entre as filosofias da diferença são as ideias de Nietzsche: "primeira referência de tal filosofia, horizonte comum entre os filósofos da diferença -, para combater a concepção essencialista, elogiar a aparência, trazer para dentro da filosofia (...) a dimensão da imanência, as multiplicidades (...)" (HEUSER, 2008, p. 60-61).

\section{Angulações nietzschianas}

\footnotetext{
${ }^{4}$ Escolhemos o termo indiferençar para distinguir de indiferenciar, que pode remeter a uma diferença por mediação.
} 
O que seriam as palavras para o filósofo alemão? "A reprodução de um estímulo nervoso em sons. Mas deduzir do estímulo nervoso uma causa fora de nós já é o resultado de uma aplicação falsa e injustificada do princípio de razão" (NIETZSCHE, 2008, p. 30). Tomemos como exemplo a palavra dois.

Segundo Nietzsche, há um estímulo nervoso do contato entre corpos distintos. Para que possamos aprender - e apreender - o conceito dois, precisamos de corpos iguais e aos pares - dois carros, duas garrafas, duas canetas - e no contato com o nosso corpo, iniciamos o processo de transformar o estímulo nervoso em som. Dois para indicar dois corpos iguais no contato conosco. Após essa relação, a partir de estímulos nervosos semelhantes, buscamos uma característica comum aos conjuntos de dois elementos. A saber, o par; o duplo. Após esse processo de estímulo nervoso e produção de som, buscamos conservar a noção de dupla, de par, para validar a aplicação da palavra dois para fora da relação com os pares; destituindo o estímulo nervoso entre nosso corpo e a materialidade dos objetos em questão como uma constatação do princípio da razão.

Propomos um movimento de pensar com as redes que interseccionam as palavras, seus conceitos, suas construções. Ao tensionar esse emaranhado de constructos, temos que

[...] o que conta nunca é a verdade, jamais uma expressão adequada: pois, de contrário, não haveria tantas línguas. A coisa em si (ela seria precisamente a pura verdade sem quaisquer consequências) também é, para o criador da linguagem, algo totalmente inapreensível e pelo qual nem de longe vale a pena esforçar-se. Ela [a palavra] designa apenas as relações das coisas com os homens [...] (NIETZSCHE, 2008, p. 31).

Modos de escrever e de pensar a escrita nos interessam como operação de resistência aos modelos instituídos de direcionamento de pensamento, ao passo que os modos de verdizer-ler o mundo passam necessariamente pela linguagem. Assumimos aqui uma contraposição à noção de inspiração como milagre, como se uma ideia "caísse do céu como um raio de graça". "Todos os grandes foram grandes trabalhadores, incansáveis não apenas no inventar, mas também no rejeitar, eleger, remodelar e ordenar" (NIETZSCHE, 2005, p. 111).

Nietzsche nega a possibilidade de "uma inspiração imediata sem trabalho interior precedente, ou seja, um milagre. [...] O capital apenas se acumulou, não caiu do céu." (NIETZSCHE, 2005, p. 111). Criar, inventar, exige repetição, corte, estudo, trabalho precedente. Essa noção é retomada de maneira direta, no aforismo 162 de Humano, Demasiado Humano: "Também o gênio não faz outra coisa senão aprender antes a assentar pedras e depois construir, sempre buscando matéria-prima e trabalhando". "Só não falem de dons e talentos inatos" (NIETZSCHE, 2005, p. 116).

Apoiando-nos, então, nessa concepção de que se faz importante escrever e pensar a própria escrita e da necessidade desse capital - que aqui chamaremos de inventário -, do assentamento de pedras que precede a criação e depende de muito trabalho, que sugerimos o estudo morfológico, etimológico e léxico-semântico em aulas de matemática - auxiliados, muitas vezes, pela história da matemática.

A partir da noção nietzscheana de trabalho sobre prevalecendo à inspiração, consideramos importante que o aluno construa um inventário, um arquivo sobre o qual ele possa se debruçar. Sem isso, nós restringimos as palavras aos seus usos comuns, mantendoas dentro das fronteiras da disciplina. Para esta construção, traçamos três pontos a serem trabalhados em aula, que a nível metodológico estão separados, mas que implicam-se mutuamente: 


\subsection{A ampliação do vocabulário}

\subsection{A relação entre palavras por derivação}

3.3. A polissemia - os diferentes significados (prontos e corriqueiros) de uma mesma palavra.

Cabe a ressalva que, além do imbricamento entre esses três aspectos, eles também não compreendem a totalidade de possibilidades de discussão sobre linguagem em aulas de matemática. Antes disso, tratam-se de pontos que consideramos importantes pela recorrência em que aparecem - ou poderiam aparecer - em nossas aulas. Mas este é um primeiro e incipiente passo na direção de abrir as aulas de matemática às discussões da linguagem e de seu estudo das palavras. Cabe a cada professor a transcriação de modos de operar com a língua e de inscrever o dinamismo do cotidiano e as forças de atravessamento da vida no que se faz aula. Transcriação, aqui, assume "uma concepção de linguagem não instrumental; não fundada na transitividade da função referencial; nem centrada na comunicação, e sim, na nomeação" (CORAZZA, 2015, p. 112) em derivação à função poética.

A seguir, discutiremos um pouco mais sobre cada ponto enumerado acima como pontos de partida (ou embarque) a uma aula que baricentra a palavra.

\subsection{A ampliação do vocabulário}

\section{vo·ca·bu·lá·ri·o \\ substantivo masculino}

1. Lista alfabética, explicativa ou não, de palavras de uma língua ou das palavras usadas numa ciência ou arte.

2. Conjunto das palavras empregadas numa ciência, arte ou indústria.

3. Conjunto das palavras de uma língua. = LÉXICO

A ampliação do vocabulário é tomada como um movimento contrário ao automatismo do uso das palavras. Enquanto recorte lexical da língua, tomemos as palavras como elementos do conjunto $\mathrm{V}=$ \{Vocabulário\}. Alargar a quantidade de elementos desse conjunto não o tornará infinito, mas a quantidade de elementos influencia diretamente no número de combinações possíveis entre elementos deste conjunto.

Operar descodificações passa por uma incidência nos códigos e, nesse sentido, as palavras - que pertencem ao campo das codificações - tornam-se condições de possibilidade para esse processo. E faz-se importante destacar também que sinônimos não são equivalências - até porque discutimos a própria significação estanque de um vocábulo. Assim, ampliar o vocabulário está intimamente relacionado à produção de rachaduras no significado estanque que as palavras vão adquirindo por hábito - e esta ampliação não é condição única e suficiente para esse movimento de "rachar as coisas, rachar as palavras" (DELEUZE, 2013), mas o assentamento de algumas primeiras pedras neste caminho. A seguir, sugerimos outras possibilidades para compor este trajeto.

\subsection{A relação entre palavras por derivação}

Consideramos a relação entre as palavras por derivação o arranjamento entre afixos e bases - sem discutirmos a diferença linguística entre derivação e flexão - ou pela combinação de mais de uma base. É aqui que se insere a discussão em nível morfológico. É comum apresentarmos geometria pela junção de geo (Terra) e metria (medida), mas menos frequente a discussão de fração, fractal e fratura: 


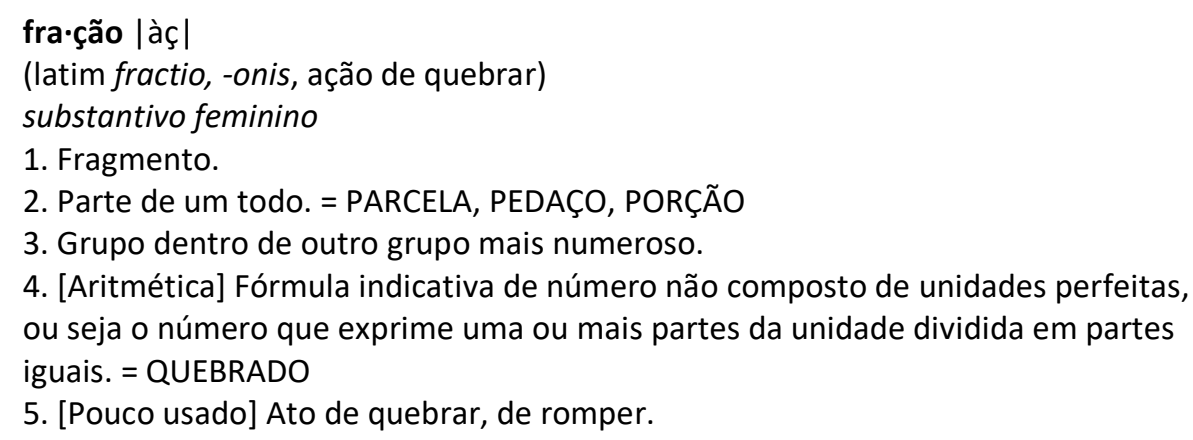

Ou a relação entre (número) primo e primeiro, entre outros tantos vocábulos que usamos em aulas de matemática.

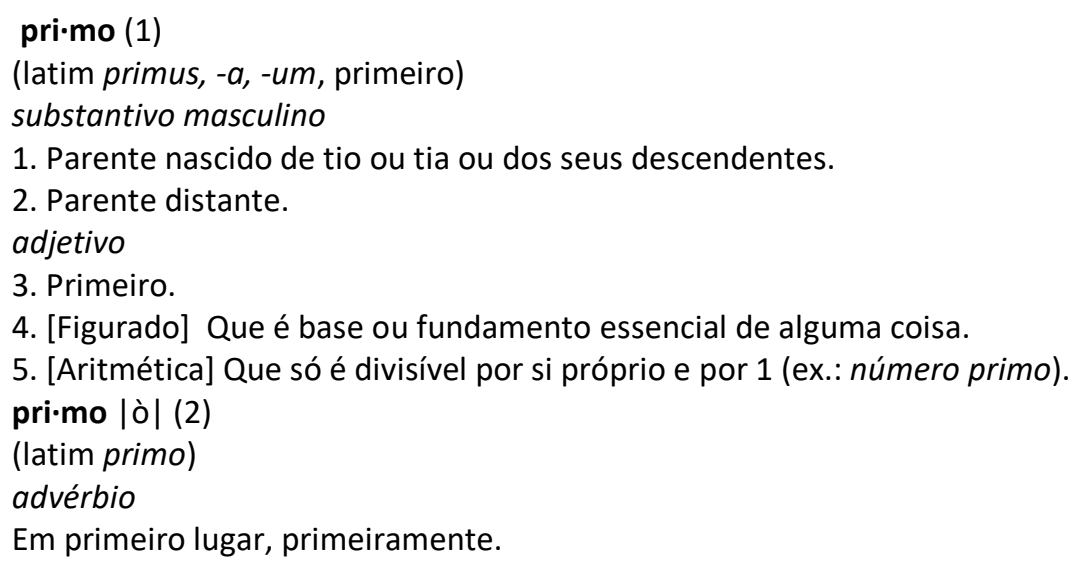

Em alguns casos, os prefixos são discutidos, como equi- ou bi-, mas parece haver uma supressão de palavras que partilham desse uso. Por exemplo: discute-se bimestre como "um período de dois meses" e bidimensional como "aquilo que possui duas dimensões", mas suprime-se bissetriz ou bissectar como elemento desse conjunto. Ou, ainda, cria-se uma suposta - e insistente, talvez por isso (pré-)suposta - distinção entre palavras de dentro e de fora do escopo da matemática: equiângulo, equidistante, equivalente, equilátero possuem o prefixo equi- em comum, mas equilíbrio não precisaria ser discutido, por exemplo.

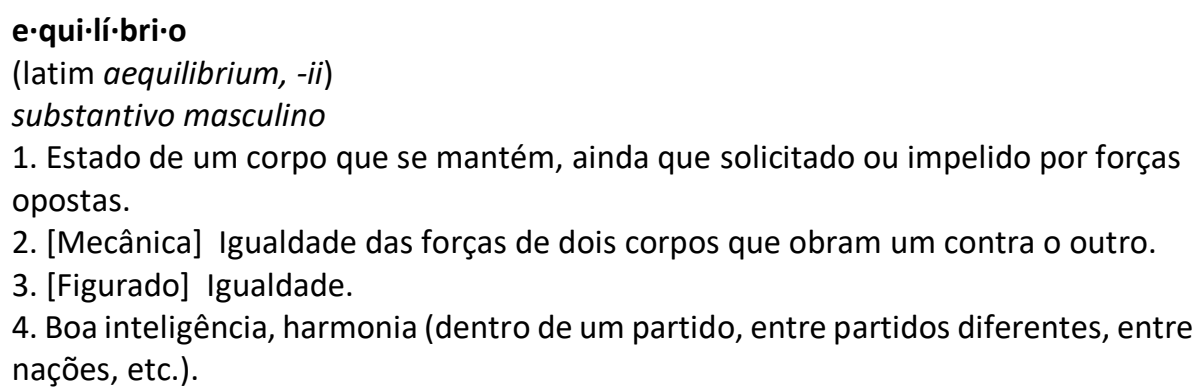

Estejamos atentos às normatizações disciplinares que nos cercam. A disciplina, para Foucault, assume dois sentidos, não sem relações entre eles. O que destacamos aqui é o 
sentido de limitação do discurso, como uma forma interna de controle do que é válido ou não ser dito. Interno "visto que são os discursos eles mesmos que exercem seu próprio controle" (FOUCAULT, 2010, p. 21). Segundo o autor, tratam-se de princípios de classificação, ordenação e distribuição dos discursos, que tornam verdadeiro - ou não - o que é dito. "Uma disciplina se define por um conjunto de métodos, um corpus de proposições consideradas verdadeiras, um jogo de regras e definições, de técnicas e de instrumentos" (FOUCAULT, 2020, p. 30).

Desse modo, as disciplinas limitam e controlam o discurso - e aqui os discursos se assumem práticas - para que um saber assuma caráter de verdade. A disciplinarização dos saberes, assim, conduz modos de pensar e estabelece os objetos dos quais podemos ou não falar, em que campo podemos ou não inscrever nosso conhecimento. Segundo Foucault, a resistência aos procedimentos de controle e delimitação do discurso - incluindo aqui a disciplinarização - passa pela suspensão da soberania do significante, pelo questionamento da vontade de verdade e pela restituição do discurso como acontecimento (FOUCAULT, 2010).

O estudo morfológico das palavras deve ser orientado sob uma perspectiva que considera que as palavras não portam significados de antemão - um trabalho de resistência às significações soberanas. Estendendo esta noção, e considerando os morfemas em sua estreita relação ao significado, faz-se necessária uma atenção aos diferentes sentidos que as palavras assumem em contextos diversos. A morfologia não pode ser trabalhada sem dois aspectos pertinentes: o estudo léxico-semântico e os questionamentos de condicionamento de verdade a que se relacionam.

O termo léxico-semântico pode ser entendido como uma composição entre o conjunto de palavras disponíveis na língua e suas relações de sentido. Assim, um estudo léxicosemântico se apresenta em níveis mais flexíveis que o campo da morfologia, ao abarcar, na engrenagem dos contextos, a temporalidade e a espacialidade dos usos.

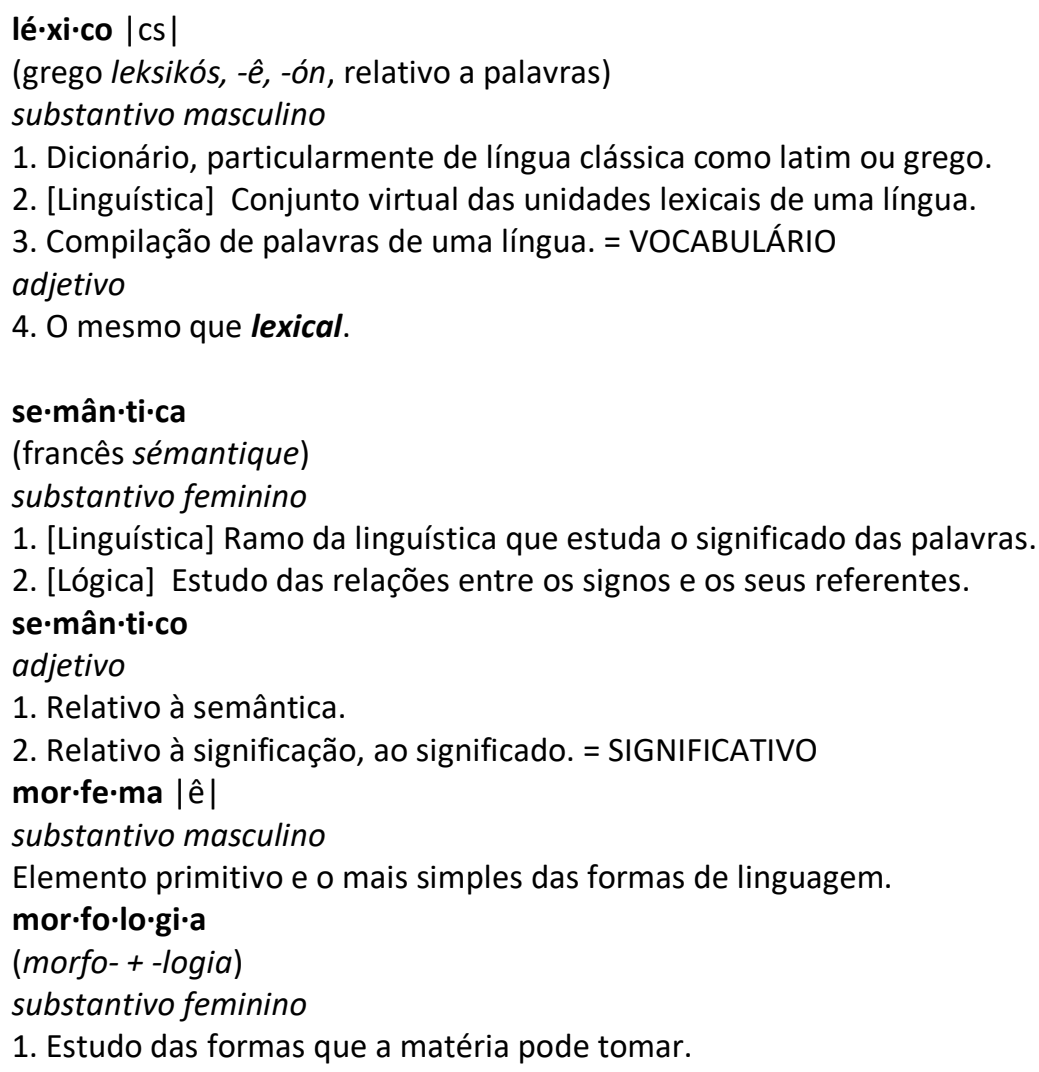

1. Estudo das formas que a matéria pode tomar. 
2. Aparência externa de um ser vivo. = CONFIGURAÇÃO, FORMA

3. [Gramática] Parte da Gramática que trata da forma e dos processos de formação das palavras.

Além disso, entra em questão o condicionamento de verdade a que determinados morfemas se constituem. Com isso, os significados assumidos pelos morfemas são valorados como verdades atemporais, e faz-se necessário estar atento a essas determinações. Vejamos um exemplo etimológico:

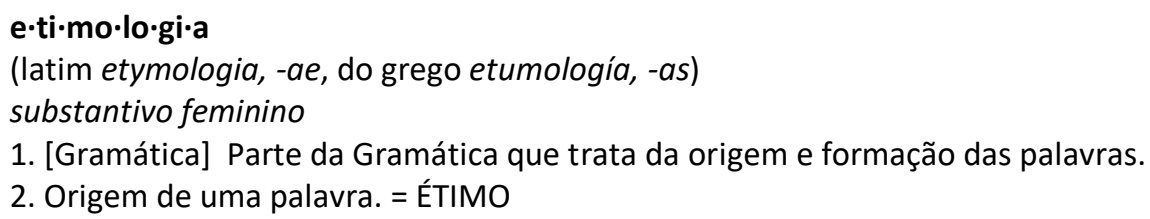

Etimologicamente, a palavra Real deriva do lat. Realis, produtora do adjetivo realeza como qualidade, hábitos e costumes do rei, dos nobres. Em relação aos costumes do rei, a realeza institui o adjetivo; nobreza. Realitas emerge na escolástica para definir "a individualidade, que consistiria na 'última realidade do ente', que determina e contrai a natureza comum [...] à coisa singular". Realidade como definição real; direitos reais: direitos pertencentes às coisas e não às pessoas. (ABBAGNANO, 2012, 976). Historicamente o real, bem como o conjunto constituidor da realeza e da nobreza (enquanto título moral) criam condições para que o status quo de real/realidade seja constituído.

Em alguns casos, a origem etimológica da palavra condiciona seu sentido, mas ainda assim produz usos variados de um mesmo vocábulo. Um exemplo é a palavra cálculo que deriva do Lat. calculus significando pedrinha. Historicamente, os "antigos utilizavam pequenas pedras nas operações aritméticas elementares" como soma e subtração. Por sua vez, o cálculo patológico do cálculo renal, é interpretado como "concreção que se forma na vesícula biliar, na bexiga" (CUNHA, 2010, p.115). Ou seja, reverbera o sentido inicial de pedrinha no escopo da perspectiva médica. Esse caso nos leva à discussão da polissemia.

\subsection{A polissemia}

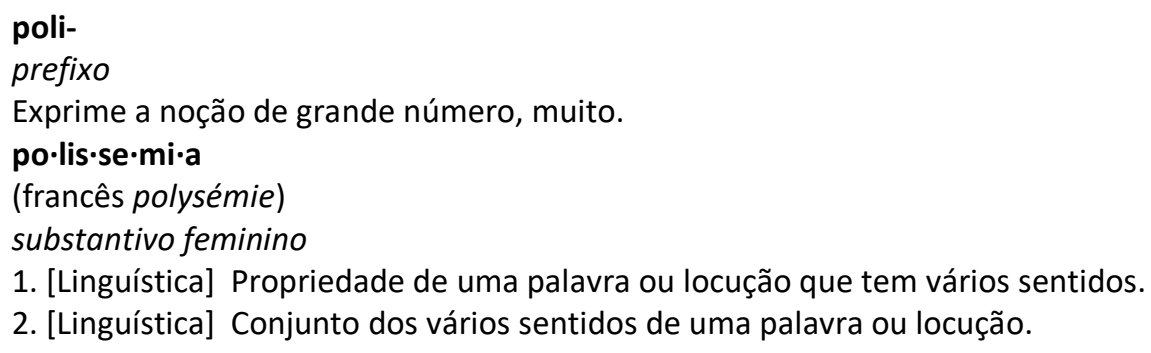

O prefixo poli- tem origem grega (polýs, noגúc) e remete à ideia de muitos, numerosos,

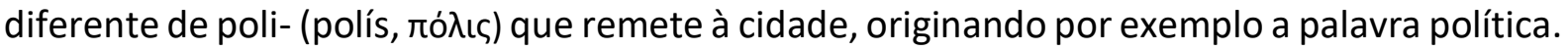
Polissemia é o estudo dos diferentes sentidos de uma mesma palavra. Estes sentidos mantêm relações, diferente do que acontece entre palavras homônimas. Um exemplo é a palavra cálculo, citada acima. O prefixo poli- é amplamente usado em matemática, como polígono, poliedro, polinômio. Este exemplo nos indica o imbricamento entre polissemia e o estudo morfológico, léxico-semântico e de ampliação vocabular.

Para um estudo polissêmico, é preciso atentar ao fato de que a separação "aula de matemática" e "vida" é uma construção e se faz urgente sua contestação. A vida acontece 
enquanto a aula acontece. Não interrompemos a vida para a execução de uma aula. Fazemos esta ressalva porque os sentidos das palavras se atravessam, estabelecem relações, e separar os sentidos entre "dia-a-dia" e "em matemática" não contribui para o estabelecimento de conexões. Palavras como plano, face, produto, razão, diferença, massa, grama, raiz, raio e chaves, por exemplo, apresentam mais de um significado conhecido por alunos da escola básica, oferecendo-se como possibilidades de iniciar o estudo da polissemia.

Os nomes dados aos conjuntos numéricos também nos abrem inúmeras possibilidades de discussão dos sentidos das palavras, que pode iniciar em um trabalho a partir da polissemia e seguir ao estabelecimento de novas relações. Quais os sentidos das palavras natural, inteiro, racional, irracional, real e imaginário? Qual a naturalidade, a espontaneidade, da abstração que chamamos número? Quando o negativo é substantivo e quando ele se torna adjetivo? Qual a realidade de algo imaginado? Qual a racionalidade de dízima periódica? Quantas outras questões podem surgir?

\title{
4 Das potências da palavra em aulas de matemática
}

\author{
po·tên·ci·a \\ (latim potentia, -ae, poder, força) \\ substantivo feminino \\ 1. Poder, força. \\ 2. Vigor, robustez. \\ 3. Autoridade, mando. \\ 4. Personagem de grande importância e influência. \\ 5. Estado, nação. \\ 6. Conjunto de aptidões ou elementos próprios para produzir um ser ou um .ato. \\ 7. [Mecânica] Força com que se equilibra ou se vence uma força contrária. \\ 8. Ponto em que aquela força se aplica. \\ 9. [Matemática] Produto de um número multiplicado por si uma ou mais vezes. \\ 10. [Filosofia] Faculdade (do espírito).
}

Ao invés de sonhar com as prescrições de uma matemática que esteja em tudo (SANTOS, 2018), movimentamos o campo matemático produzindo rupturas, desconstituindo fronteiras. Não há necessidade de recorrer a elementos ditos da natureza humana para justificar aprendizagens e conceitos matemáticos. As tendências que muitas vezes regem os currículos compreendem que a matemática seria uma linguagem através da qual podemos ter acesso à realidade, explicá-la, compreendê-la. Para as filosofias da diferença, a linguagem não decifra a realidade, ela a constrói.

Não defendemos que a matemática esteja presa em si mesma, que possua caráter estático ou independente. Também não defendemos que ela precise de algo para além de suas fronteiras para se sustentar ou para adquirir significado. Nos questionamos: quais as potencialidades de tensionar seus saberes a partir de seus nomes, de sua semântica, de sua história e seus usos? Quais os limites que podemos esgarçar entre matemática e língua materna? Quais os impensados da linguagem que se abrem ao discutirmos a própria linguagem assentada em alicerces da disciplina de matemática? De que maneira as práticas de significação que se legitimam em uma suposta neutralidade e transparência da linguagem conduzem modos de pensar e instauram verdades?

A adjetivação de substantivos consiste numa ação combinatória da linguagem, então cabe perguntar: Quais são os adjetivos para a matemática ensinada na escola básica? Moralista, idealizadora, produtora do bem e do mal, tradutora da realidade, bruxa, monstra, 
santa (BAMPI, 1999). "Quanto de adjetivação comporta uma matemática? Quanto suporta uma matemática ser adjetivo e não substantivo?" (CLARETO; MIARKA, 2015, p. 794). Para além desses adjetivos, o que conseguimos operar e produzir com matemática na escola básica?

Atentos ao movimento movediço-fronteiriço-impulsionador dos questionamentos, afirmamos as alegrias, pois "não com a ira, mas com o riso é que se mata". E com a alegria "[...] sou leve, agora voo, agora me vejo abaixo de mim, agora dança um deus através de mim" (NIETZSCHE, 2018, p. 40). E, igualmente, os não reconhecimentos do que se dá com o uso das palavras no ensino da matemática. A potência da diferença faz seu lar (fazer é construir, com gravetos, a cada aula, em aula) no rompimento com a identidade. Potência, aqui, se dá por expansão ou encolhimento de acordo com as relações estabelecidas ${ }^{6}$. Diferença se faz por processos de derivação e integração, diferenciação e diferençação (DELEUZE, 2009). Pensar a potência da diferença, nesta acepção, se faz possível por conhecimentos matemáticos aprendidos e discutidos, contextualizados neste uso, a partir de determinadas leituras e acompanhados de autores escolhidos. Ou seja, nosso repertório de matemática possibilita o redimensionamento de nosso pensamento e serve de ferramenta para sua operação.

\section{re.per·tó·ri·o}

(latim repertorium, -ii, inventário, catálogo)

substantivo masculino

1. Índice alfabético das matérias contidas num livro.

2. Livro em que se fazem menções sucintas ordenadas pela ordem cronológica ou segundo a analogia dos assuntos para facilitar a consulta.

3. [Pouso usado] Folha ou livro impresso com indicações dos dias, meses, estações do ano, fases da lua, feriados. = ALMANAQUE, CALENDÁRIO, FOLHINHA.

4. Conjunto das composições representadas por um ator, por um grupo de teatro o $\mathrm{u}$ interpretadas por grupo musical, músico ou cantor.

5. Coleção das obras teatrais ou musicais de um autor, de um compositor, de uma escola, de um estilo.

6. Conjunto das composições representadas ou interpretadas em um espetáculo teatral ou musical. $=$ PROGRAMA

7. Compilação de elementos da mesma natureza.

8. [Figurado] Conjunto de conhecimentos.

9. [Figurado] Pessoa muito versada em determinados temas.

10. [Antigo] Conjunto de sintomas de certas doenças, especialmente reumáticas.

11. [Jurídico, Jurisprudência] Coletânea de leis, pareceres e documentos oficiais.

\section{Matemática e a atribuição de sentidos - procedimentos genealógicos}

Proceder genealogicamente produz aproximações com a história. Não a história cartesiana, linear, narradora de si e sonhadora de uma razão capaz de encadear todos os fatos. Aproximar-se da história como zona proximal, como margem: escapar das grandes narrativas

\footnotetext{
${ }^{5}$ Em Crepúsculo dos ídolos (2017), Nietzsche constitui a metáfora do martelo para romper com ídolos; ideais. 0 "livro é uma grande declaração de guerra; e, quanto ao escrutínio de ídolos, desta vez eles não são ídolos da época, mas ídolos eternos, aqui tocados com o martelo como se este fosse um diapasão - não há, absolutamente, ídolos mais velhos, mais convencidos, mais empolados... E tampouco mais ocos... Isso não impede que sejam os mais acreditados" [...] (NIETZSCHE, 2017, p. 7-8), [grifos do autor].

${ }^{6}$ Uma potência com base $b>1$ elevada a um expoente $n>1$, por exemplo, resultará em um valor final maior que a base inicial; já uma base $0<b<1$ elevada a um expoente $n>1$ resultará em um valor final menor que a base dada (outros tantos casos podem ser discutidos acerca da expansão ou encolhimento da potência).
} 
que enclausuram acontecimentos - ou seus efeitos. Trata-se de operar por tangenciamento, no intuito de afirmar a provisoriedade das atribuições de sentidos, de valores emergentes.

\section{tan'gen'ci·ar}

verbo transitivo

1. [Brasil] Seguir a tangente de.

2. Tocar.

3. Roçar por.

4. Relacionar-se com.

\section{tan'gen $\cdot$ te}

adjetivo de dois gêneros

1. Que tange, que toca.

2. [Geometria] Que toca uma linha ou uma superfície num só ponto.

substantivo feminino

3. [Geometria] Linha reta que toca um plano ou outra linha num só ponto

(símbolo: $t g$ ).

No escopo de uma interpretação marginal e minoritária (DELEUZE; GUATTARI, 2017; CLARETO, 2010), traçamos (des)encontros em pontos produzidos por fugas necessárias aos modelos, recursos, padrões.

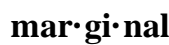

(latim tardio marginalis, -e)

adjetivo de dois gêneros

1. Da margem.

2. Que está à margem de um texto (ex.: anotação marginal).

3. Situado nas margens de um curso de água (ex.: zona marginal).

$=$ JUSTAFLUVIAL, RIBEIRINHO

4. [Figurado] Diz-se do assunto, questão, aspecto, etc., de importância

secundária e escassa (ex.: personagem marginal). = ACESSÓRIO, MENOR,

SECUNDÁRIO $\neq$ ESSENCIAL, FUNDAMENTAL, PRINCIPAL

adjetivo de dois gêneros e substantivo de dois gêneros

5. Que ou quem vive à margem da sociedade, desrespeitando leis, costumes e valores estabelecidos (ex.: atitudes marginais; vida de marginal).

$=$ DELINQUENTE, VAGABUNDO

substantivo feminino

6. Estrada ou rua junto à margem ou junto a uma grande extensão de água (ex.: $a$ remodelação da marginal contempla a instalação de novos candeeiros públicos).

Ao afastar-se do ideal - com o auxílio do martelo - truncamos, arrancamos, produzimos perspectivas outras aquém das "colmeias do conhecimento". "Estamos sempre a caminho delas, sendo por natureza criaturas aladas e coletoras do mel do espírito, tendo no coração apenas um propósito - levar 'algo para casa'" (NIETZSCHE, 2009, p. 7). Ao levar "algo para casa" esquecemo-nos das vivências que impulsionam a diferença frente ao doce mel dos saberes lineares, das verdades totalizadoras. Para rompê-las e evidenciar uma verdade indefinida, sem marcadores, articulamos rupturas com os sentidos estanques em aulas de matemática.

Para produzir sentidos outros e mobilizar as certezas do conhecimento, operamos uma "leitura como arte" (NIETZSCHE, 2009). Aprendemos tal procedimento com Nietzsche ao ruminar os saberes, as verdades, os conhecimentos. Ao questionar os valores, alçamos possíveis perspectivas para enxergar de outros modos; menos fixos; mais movediços. Ao analisar o que esteve (in)visível conosco, ampliamos sentidos, produzimos novos significados.

As aproximações com a história não produzem uma constatação de fatos, uma verificação de supostas morais, mas sim uma rede de relações, de saberes e poderes que se 
interpelam e engendram visibilidades e dizibilidades que até alguns instantes atrás não podiam ser enunciadas (FOUCAULT, 2010). Ao proceder contemporaneamente, recorremos à história, à etimologia, ao sentido léxico-semântico das palavras buscando interpretações que proliferam modos de pensar que são nossos; do contemporâneo. As tramas necessárias para que certos significados possam emergir não se encontram paralelas a nós

Ao tomar distanciamento do nosso tempo, produzimos ferramentas capazes de tensionar nossos valores. Assim, (re)afirmando que não existem "fenômenos morais", mas "uma interpretação moral dos fenômenos" (NIETZSCHE, 2005). Ao interpretar, lançamos medidas, ângulos, circunscrições menos em direção a um modo único de conhecer uma palavra e sim pelo percurso minoritário de interpelar, ruminar, digerir as palavras para fazer variar perspectivas e, com isso, expandir fronteiras, sentidos, significados em aulas de matemática.

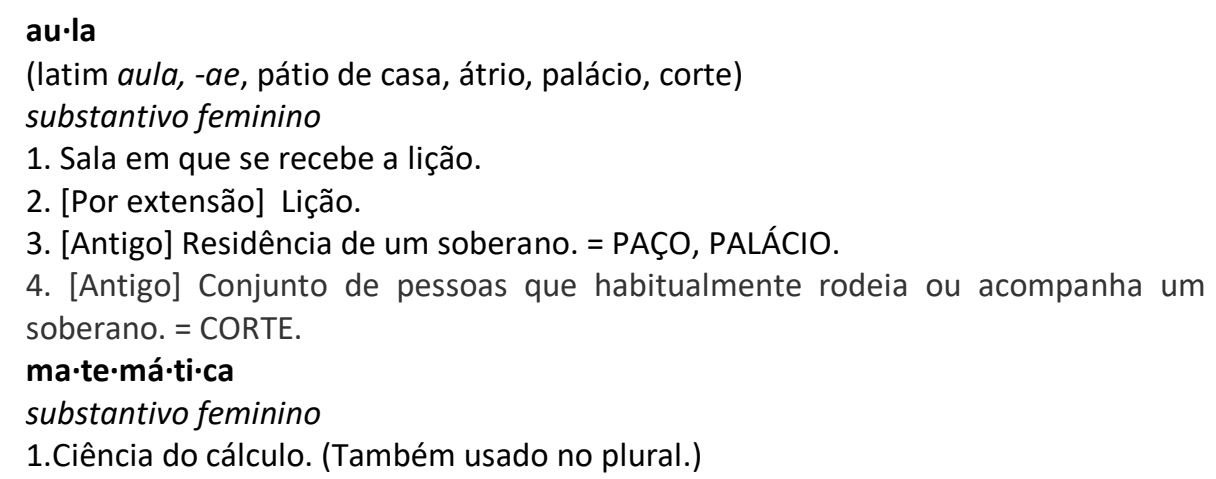

E o que mais?

\section{Conclusões (resultantes/produtos/implicações)}

O processo de romper com o igual permite a ampliação ou a diminuição da potência de agir em vida que se faz aula. Neste rompimento, a docência e o ensino sorriem-sofrem, se constituem pelo meio, se elaboram em função da diferença. Não há como viver diferenças em cada aula, em todos os períodos, se considerarmos a diferença em si, ou seja, produto e produtora de movimentos, de impensados, de distanciamento de normas, prescrições e parâmetros. Questionamos o quão solitária está uma matemática que esquece seus percursos para buscar em um bosque - supostamente encantado ${ }^{7}$ - ideias, representações, modelos, perfeições? O sonho dos matemáticos é sedutor, como nos expõe Walkerdine (2007, p. 11).

Problematizar as palavras, para nós, produz variações com a matemática. Ao movimentá-la em aula, produzimos semelhanças, diferenças, outros modos de estar com. Juntos, perspectivando não o que a matemática seja, mas aquilo que fazemos com que ela seja. A perspectiva nietzscheana nos lança ao deslocamento, porque o filósofo anuncia a impossibilidade de uma fundamentação última da linguagem.

Sabemos o quão arriscado se torna exemplificar de que maneira operamos um processo de desmontagem e ressignificações de palavras em aulas de matemática, porque não desejamos fornecer modelos ou estabelecer paradigmas ou métodos de ensino ou planejamento de aula (menos ou e mais $e$ ). Mas consideramos que trazer alguns dos

\footnotetext{
${ }^{7}$ O encantamento aqui faz alusão ao sonho da Razão que "vislumbra o sucesso da raça humana em direção a uma moral universal e à auto-realização intelectual e ao progresso baseado em uma razão científica, universal, educadora", ao grande projeto da filosofia denominado Razão Universal (HEUSER, 2005, p. 61).
} 
tensionamentos que surgiram em nossa prática com alunos da escola básica poderia servir como disparamento para maneiras outras de pensar a palavra - as palavras, o palavrear - no ensino de matemática. Desse modo, esperamos que outros questionamentos surjam, que conversações com a linguagem e com as filosofias da diferença adentrem o espaço e o tempo da aula, produzindo olhares, dizeres, desejos, efeitos diversos.

\section{Referências}

ABBAGNANO, Nicola. Dicionário de filosofia. Trad. Alfredo Bosi. 6 ed. São Paulo: WMF Martins Fontes, 2012.

AURICH, Grace Da Ré. Reescrita de Si: a Invenção de uma Docência em matemática. Porto Alegre, 2017. 152f. Tese (Doutorado em Educação) - Programa de Pós-Graduação em Educação. Faculdade de Educação. Universidade Federal do Rio Grande do Sul, Porto Alegre, 2017.

BAMPI, Lisete Regina. O discurso da Educação Matemática: um sonho da Razão. Porto Alegre, 1999. : Dissertação (Mestrado em Educação) - Programa de Pós-Graduação em Educação. Faculdade de Educação. Universidade Federal do Rio Grande do Sul, Porto Alegre, 1999.

BARROS, Fernando de Moraes. Introdução. NIETZSCHE, Friedrich. Sobre verdade e mentira. Tradução Fernando de Moraes Barros. São Paulo: Hedra, p. 9-21, 2008.

CLARETO, Sônia Maria. Na sala de aula de matemática: inventividade e resistência. CLARETO, Sônia Maria; DETONI, Adlai Ralph; PAULO, Rosa Monteiro (Orgs.). Filosofia, matemática e educação matemática: compreensões dialogadas. - Juiz de Fora: Editora UFJF, p. 73-86, 2010.

CLARETO, Sônia Maria; MIARKA, Roger. eDucAçÃo MAteMátiCA AefeTIvA: nomes e movimentos em avessos. Bolema, Rio Claro (SP), v. 29, n.53, p. 794-808, dez. 2015. Doi:

http://dx.doi.org/10.1590/1980-4415v29n53a01. Disponível em:

https://www.scielo.br/pdf/bolema/v29n53/1980-4415-bolema-29-53-0794.pdf. Acesso em 07 nov. 2020.

CORAZZA, Sandra Mara. Didática da tradução, transcriação do currículo (uma escrileitura da diferença). Pro-Posições. v. 26, n. 1 (76) p. 105-122. jan/abr. 2015. DOI: https://doi.org/10.1590/0103-7307201507609. Disponível em: https://www.scielo.br/pdf/pp/v26n1/0103-7307-pp-26-01-0105.pdf. Acesso em 07 nov. 2020.

CORAZZA, Sandra. TADEU, Tomaz. Composições. - Belo Horizonte: Autêntica, 2003.

CUNHA, Antônio Geraldo da. Dicionário etimológico da língua portuguesa. 4 ed. Rio de Janeiro: Lexikon, 2010.

DELEUZE, Gilles. Conversações. Trad. Peter Pál Pelbart. São Paulo: Editora 34, 2007.

DELEUZE, Gilles. Diferença e Repetição; tradução Luiz Orlandi, Roberto Machado. Rio de Janeiro. Graal, 2009.

DELEUZE, Gilles; GUATTARI; Félix. Kafka: por uma literatura menor. Trad. Cíntia Vieira da Silva. 1 ed. Belo Horizonte: Autêntica Editora, 2017. 
DICIONÁRIO PRIBERAM DE LÍNGUA PORTUGUESA. Disponível em

$<$ https://dicionario.priberam.org/>. Acesso em 04 jul 2020.

FOUCAULT, Michel. A ordem do discurso. 20 ed. Edições Loyola, São Paulo, 2010.

HEUSER, Ester Maria Dreher. No rastro da filosofia da diferença. SKLIAR, Carlos (org.). Derrida e educação. 1. Ed. Belo Horizonte: Autêntica, p. 59-82, 2008.

MACHADO, Nílson José. Matemática e língua materna: análise de uma impregnação mútua. 6 ed. São Paulo: Cortez, 2011.

MARCONDES, Danilo. As armadilhas da linguagem: significado e ação para além do discurso. Rio de Janeiro: Zahar, 2017.

NIETZSCHE, Friedrich. Assim falou zaratustra: um livro para todos e para ninguém. Trad. Paulo César de Souza. 1 ed. São Paulo: Companhia de Bolso, 2018.

NIETZSCHE, Friedrich. Crepúsculo dos ídolos, ou como se filosofa com o martelo. Trad. Paulo César de Souza. 1 ed. São Paulo: Companhia de Bolso, 2017.

NIETZSCHE, Friedrich. Genealogia da moral: uma polêmica. Tradução Paulo César de Souza. São Paulo: Companhia das Letras, 2009.

NIETZSCHE, Friedrich. Humano, demasiado humano: um livro para espíritos livres. Trad. Paulo Cesar de Souza. São Paulo: Companhia das Letras, 2005.

NIETZSCHE, Friedrich. Sobre verdade e mentira. Trad. Fernando de Moraes Barros. São Paulo: Hedra, 2008.

PESSOA, Fernando. Livro do desassossego. São Paulo: Ciranda Cultural, 2019.

RÉGNIER, Jean-Claude; BELLO, Samuel Edmundo Lopez; KUZNETSOVA, Ekaterina M. Uma abordagem normativa para a etnomatemática: bases linguísticas e filosóficas. In: Santos, Gilberto Silva; SPERRHAKE, Renata; BELLO, Samuel Edmundo Lopez (orgs). Abordagens filosóficas contemporâneas em educação: docências, matemáticas e subjetivações. São Leopoldo: Oikos, p. 42-63, 2018.

Disponível em: http://oikoseditora.com.br/new/obra/index/id/939. Acesso em 07 nov. 2020.

SANCHOTENE, Virgínia Crivellaro. A impossibilidade da permanência: conversas com Foucault e Deleuze. 2. ed. Porto Alegre: Canto: Cultura e Arte, 2017.

SANTOS, Gilberto Silva. Pedagogia da realidade e educação matemática: entre as docências escrava e nobre. Texto digitalizado, 2020.

SANTOS, Gilberto Silva dos. O saber-realidade e a constituição docente: tramas da educação matemática contemporânea. Em Teia: Revista de Educação Matemática e Tecnológica Iberoamericana, v. 9, n. 2, on-line, 2018. DOI: https://doi.org/10.36397/emteia.v9i2.237639. Disponível em: https://periodicos.ufpe.br/revistas/emteia/article/view/237639. Acesso em: 03 jun. 2020. 
SILVA, Tomaz Tadeu da. $\mathbf{O}$ currículo como fetiche: a poética e a política do texto curricular. Belo Horizonte: Autêntica, 1999.

SILVA, Tomaz Tadeu da. Documentos de identidade: uma introdução às teorias do currículo. 2 ed. Belo Horizonte: Autêntica, 2005.

SPERB, Carolina. CORAZZA, Sandra Mara. DINARTE, Luiz Daniel Rodrigues. Ciência, filosofia e arte escrileitora na/da escola. Revista Teias v. 18, n. 50, jul/set 2017.

DOI: https://doi.org/10.12957/teias.2017.26678. Disponível em: https://www.e-

publicacoes.uerj.br/index.php/revistateias/article/view/26678/21653. Acesso em 07 nov. 2020.

WALKERDINE, Valerie. Ciência, razão e mente feminina. Trad. Francisco Egger Moellwald. Educação e Realidade, v. 31, n. 1, p. 7-24 Porto Alegre: jan/jun. 2007. Disponível em:

https://seer.ufrgs.br/educacaoerealidade/article/view/6657/3973. Acesso em 07 nov. 2020. 